\title{
EVALUATION OF FACET, SACRAL AND FORAMINAL INFILTRATIONS IN THE TREATMENT OF LOW BACK PAIN
}

\author{
AVALIAÇÃO DAS INFILTRAÇÕES FACETÁRIAS, SACRAIS E FORAMINAIS NO TRATAMENTO \\ DAS LOMBALGIAS
}

EVALUACIÓN DE LAS INFILTRACIONES FACETARIAS, SACRALES Y FORAMINALES

EN EL TRATAMIENTO DEL DOLOR LUMBAR

Fernando Luiz Guedes Lauda', Maurício Fernandes de Camargo ${ }^{1}$, Fernando Vaguetti Lauda ${ }^{1}$

1. Spine Surgery Service of the Instituto de Ortopedia eTraumatologia de Passo Fundo, RS, Brazil.

\begin{abstract}
Objective: The difficulties of the study and the lumbago approach stem from several factors, among them, the lack of a reliable correlation between the clinical findings and image results and the fact the lumbar segment is innervated by a network of diffuse and intertwined nerves, making it difficult to accurately determine the location of pain origin. The treatment of this disease is mainly based on conservative measures (rest, analgesia, physical therapy) and only in a few cases, the option is surgical measures. Methods: In this study, we conducted an analysis of the results obtained with foraminal, sacral and facet infiltrations of corticoids in the lumbosacral spine in a period of three months in 83 patients with low back pain. Results: The patients showed a statistically significant reduction of pain (mean value) after infiltrations (sacral, foraminal and facet), according to the Visual Analogue Scale of 4 points in the immediate postoperative period, reduction of 3.9 points at 15 days, reduction of 3.5 points at 30 days, a reduction of 3.1 points at 45 days and a reduction of 2.7 points at 90 days. Conclusion: The sacral, foraminal and facet infiltrations of corticoids to control low back pain relieves short-term pain (30 days) and medium and long-term (30-90 days), when the indication is correct.
\end{abstract}

Keywords: Low back pain; Adrenal cortex hormones; Analgesia, epidural.

\section{RESUMO}

Objetivo: As dificuldades do estudo e da abordagem das lombalgias decorrem de vários fatores, entre eles, inexistência de correlação fidedigna entre os achados clínicos e os de imagem e o fato de o segmento lombar ser inervado por uma rede de nervos difusa e entrelaçada, que torna difícil determinar com precisão o local de origem da dor. O tratamento dessa doença é principalmente baseado em medidas conservadoras (repouso, analgesia, fisioterapia) e em poucos casos, a opção é recorrer a medidas cirúrgicas. Métodos: No presente estudo, realizamos uma análise dos resultados obtidos com infiltrações foraminais, sacrais e facetárias com corticoides na coluna lombossacral em um prazo de 3 meses, em 83 pacientes com lombalgias. Resultados: Os pacientes apresentaram redução estatisticamente significante da dor (valor da média) depois das infiltrações (sacrais, foraminais e facetárias), segundo a Escala Visual Analógica de 4 pontos no pós-operatório imediato, redução de 3,9 pontos aos 15 dias, redução de 3,5 pontos aos 30 dias, redução de 3,1 pontos aos 45 dias e redução de 2,7 pontos aos 90 dias. Conclusão: As infiltrações sacrais, foraminais e facetárias de corticoides para controle das lombalgias alivia a dor a curto (30 dias), médio e longo prazo (30 a 90 dias), quando são indicadas corretamente.

Descritores: Dor lombar; Corticosteroides; Analgesia epidural.

\section{RESUMEN}

Objetivo: Las dificultades del estudio y del abordaje de la lumbalgia se derivan de varios factores, entre ellos, no hay correlación fiable entre los hallazgos clínicos y los encontrados en las imágenes, además del hecho que el segmento lumbar está inervado por una red de nervios difusos y entrelazados lo que dificulta determinar la ubicación precisa de origen del dolor. El tratamiento de esta enfermedad se basa principalmente en medidas conservadoras (reposo, analgesia, terapia física) y en unos pocos, la opción es quirúrgica. Métodos: En el presente estudio, se realizó un análisis de los resultados obtenidos con infiltraciones foraminales, sacrales y facetarias en la columna lumbosacra, en un período de tres meses en 83 pacientes con dolor lumbar. Resultados: Los pacientes mostraron una reducción estadísticamente significativa en el dolor (valor medio) después de las infiltraciones (sacral, foraminal y facetaria), de acuerdo con la Escala Visual Analógica de 4 puntos en el postoperatorio inmediato, reducción de 3,9 puntos en 15 días, reducción de 3,5 puntos a los 30 días, una reducción de 3,1 puntos en 45 días y una reducción de 2,7 puntos en 90 días. Conclusión: Las infiltraciones sacrales, foraminales y facetarias de corticosteroides para controlar la lumbalgia alivia el dolor a corto (30 días), mediano y largo plazo (30 a 90 días), cuando se hayan indicado correctamente.

Descriptores: Dolor de la región lumbar; Corticoesteroides; Analgesia epidural.

\section{INTRODUCTION}

Throughout the entire history of mankind, pain has been one of man's greatest concerns, making it the very "raison d'être" of Medicine.
Painful lower back syndromes continue to be a public health problem, even though humanity has suffered from it for centuries. Low back pain is a major cause of morbidity and disability, surpassed only by headaches, on the scale of painful disturbances that affect man. ${ }^{1}$ 
About $80 \%$ of people, in some phase of their life, are affected by lower back pain. Despite the progress of ergonomics applied to the spine and of the use of sophisticated diagnostic methods, in the 1970s, 1980s, and 1990s, the increase in lower back pain and lumbosciatalgia was 14 times greater than that of the population itself. ${ }^{2}$

The etiological characterization of low back pain syndrome is an eminently clinical process and complementary examinations are indicated to confirm the diagnostic hypothesis. To conceptualize the terms used, one has to understand their differences. Low back pain includes all painful conditions, with or without rigidity, located in the lower regions of the back, in an area between the last costal arch and the gluteal fold. Lumbosciatalgia is the pain that radiates from the lumbar region to one or both of the inferior members. Sciatalgia/ sciatica is the uni- or bilateral pain that begins at the root of the thigh, descends past the knee, and in most cases reaches the foot, accompanied or not by motor and/or sensory deficit. ${ }^{3}$

In terms of evolution, all three can be characterized as acute, subacute, or chronic. Treatments include conservative measures that run the gamut from rest, the use of oral, topical, and parenteral medications, corticosteroid infiltrations (facet joint, conjugation foramen, or sacral hiatus), to surgery and rehabilitation. ${ }^{4}$

\section{Objective}

The objective of the study was to evaluate the use of epidural and sacral corticosteroids in the treatment of low back pain, to know the indications for sacral and foraminal corticosteroids infiltrations in low back pain syndromes, and to evaluate the analgesic effects of corticosteroid in facet, sacral, and foraminal infiltrations in the short, medium, and long term according to the VAS (the visual analog scale for pain).

\section{METHOD}

In this study, we conducted an analysis of the results obtained with foraminal, sacral, and facet infiltrations of corticosteroids in the lumbosacral spine over a period of three months in 83 patients with lower back pain.

The study was approved by the Institutional Review Board as protocol number CAAE 56350816.0.0000.5342 and the patients signed the Informed Consent Form.

\section{DISCUSSION}

Lower back pain is the second greatest cause of morbidity and work disability and is a public health issue. Despite the clinical evaluation and the progress of diagnostic methods for the confirmation of diagnostic hypothesis and good treatment, its proper study and treatment are difficult.

There need to be more studies for a better understanding of low back pain and lumbosciatalgia because there is no reliable correlation between the clinical and imaging findings.

The pathogenesis of pain in cases with compromise of the nerve root is caused not only by mechanical compression, but also by chemical irritation due to proinflammatory cytokines. Corticosteroid infiltrations can be used in the latter situation. ${ }^{5}$

Treatments include conservative measures from rest, to the use of oral, topical, parenteral medications (corticosteroids, NSAIDS, analgesics), to surgical measures. Sacral, facet, and foraminal infiltrations can be an option for the treatment and control of pain in lumbago.

\section{Research problem}

What type of patients with lumbago and lumbosciatalgia were indicated for facet, foraminal, and sacral infiltrations and what were the results?

\section{Literature review}

Localized spine pain and radiculopathy are very common conditions that affect most of the world population at some time during their lives. The accumulated prevalence varies between $60 \%$ and
$90 \%$. Initial treatment program consists of rest, oral medication with analgesic/anti-inflammatory agents, and physical therapy.

But, in $10-20 \%$ of these patients, the pain persists or recurs and the quality of life is negatively impacted, requiring additional treatment. In this evaluation, an anatomical etiology of the pain is considered. The imaging studies of choice are normally simple radiographs and magnetic resonance imaging. Morphological changes are common findings in asymptomatic patients. The results of these tests should be correlated with the clinical investigation because there is a high prevalence of morphological changes in the spine in asymptomatic patients, indicating that the correlation between pain and structural abnormality is weak. ${ }^{6}$

There are only several structural changes that often occur in symptomatic patients, i.e.: 1. compression of the nerve root; 2 . significant disc extrusion and sequestration; 3. moderate to serious changes to the facet joints; and 4. moderate to serious changes to the terminal plate.

However, most patients with lumbago and cervicalgia present few or even no structural changes (for example, protrusion of the disc, mild compression of the nerve root, and mild osteoarthrosis of the facet joint). The same changes may be found with a high prevalence in the asymptomatic population. The predictive value of magnetic resonance in the diagnosis of symptomatic disc changes is limited. ${ }^{7}$

Spinal injections studies have been advocated to differentiate symptomatic from asymptomatic lesions because of the low positive predictive value of imaging studies.

Several studies describe application techniques and potential benefits. However, the lack of a clear understanding of pain, pathogenesis, and consequently the lack of specific protocols make it difficult to measure the diagnostic impact of these infiltrations.

The logic of infiltration studies is to eliminate or provoke the patient's pain. Infiltrations can be used as a therapeutic test. ${ }^{8}$

The frequent use of spine infiltrations as a diagnostic tool indicates that these may also have therapeutic value. The second reason is the use of spinal infiltrations to support non-surgical treatment in patients suffering from nerve root involvement either from spinal stenosis or osteoarthritis of the facet joint. Despite the generalized use of spinal infiltrations, their application is largely based on professional experience and clinical results. ${ }^{9}$

\section{Lumbar nerve root block}

Selective blocks of the nerve root were described for the first time by Macnabe and Cols, working in 1971 on a diagnostic test for the evaluation of patients with no changes in imaging studies but with clinical findings of radicular irritation.

The high prevalence of asymptomatic disc herniation many times suggests the need for verification of the morphological correlation of equivocal radicular pain. ${ }^{10}$

The pathogenesis of pain in cases with involvement of the nerve root is caused not only by mechanical compression, but also by chemical irritation by cytokines. The justification for a nerve root block is therefore to treat the inflammatory component of the radicular involvement.

The periradicular foraminal nerve root block is always performed under the control of a fluoroscope, enabling direct application of corticosteroids to the nerve root. The objective of a selective block is not to cure the patient, but rather to provide relief required for the spontaneous resolution of radiculopathy during the pain peak.

Indications: Nerve root blocks are indicated for diagnosis and for therapeutic effect.

Diagnostic indications: Suspicion of sciatalgia; discrepancy between the morphological changes and the patient's symptoms; and involvement of multiple roots.

Therapeutic indications: Sciatalgia in the absence of significant neurological deficits; subacute radicular pain that does not respond to conservative treatment; mild to moderate foraminal stenosis.

Technique: Perineural infiltrations are performed in the foraminal exit. 
It should be emphasized that infiltration directly in the nerve root should be avoided due to the potential risk of permanent neurological damage. Thus, perineural infiltration is recommended. The treatment agent used for this procedure varies among the studies. Most authors use a mixture of $2 \mathrm{ml}$ of $0.25 \%$ bupivacaine and 40 $\mathrm{mg}$ of methylprednisolone. Others use $1.5 \mathrm{ml}$ of $3 \%$ lidocaine with $9 \mathrm{mg}$ of betamethasone acetate. There is no study that compares the solutions in terms of treatment outcomes. We report here the techniques used in this service.

\section{Lumbar nerve root block}

Technique: Lumbar nerve root blocks are performed under the control of a fluoroscope. The standard technique is an outpatient procedure without premedication and can be performed in a radiology room or an operating room. The patient is in the ventral decubitus with the injected side elevated at an angle of approximately 30 degrees.

The final degree of rotation is determined by the fluoroscope. The goal of positioning is to permit a perpendicular needle trajectory in the direction of the site of the infiltration under the pedicle. (Figure 1) The so-called safety triangle is defined by above by the pedicle, laterally by the side edge of the vertebral body, and medially by the external margin of the spinal nerve.

Following disinfection of the skin, a local anesthetic is administered with a 25 gauge needle. Guided by the fluoroscope, a 22 gauge needle is then advanced through a short 18 gauge needle to the safety triangle area. To access the nerve root of L5 and S1 the standard technique is adapted slightly. For the L5 root, the needle usually has to be tilted in the cranio-caudal direction in order to bypass the iliac wing. Infiltration of the root of S1 is performed via the dorsal foramens. The needle position is marked with biplanar fluoroscopy, followed by an injection of $0.3 \mathrm{ml}$ of contrast material. (Figure 2)

Fluoroscopic control images are obtained to document the distribution of the contrast material. Two milliliters of $0.2 \%$ ropivacaine and $40 \mathrm{mg}$ of triamcinolone are slowly injected.

Both pain and the neurological assessment should be evaluated before and after the block.

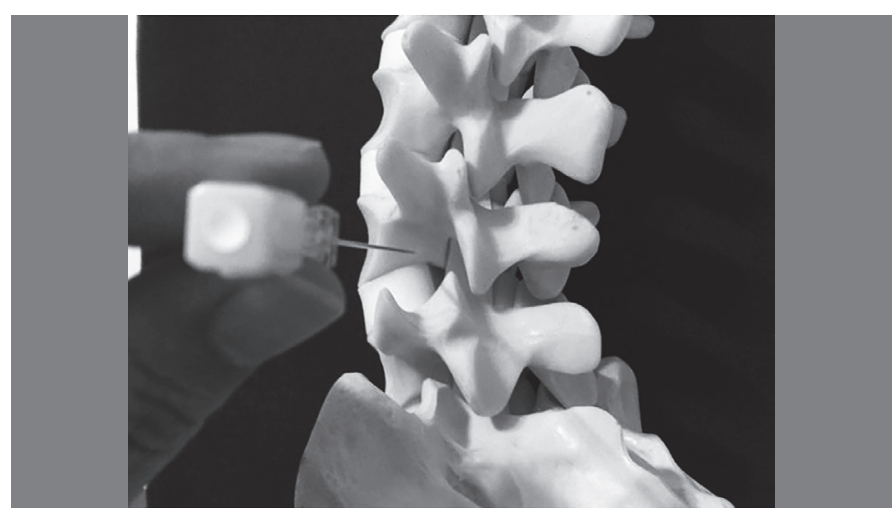

Figure 1. Foraminal space.

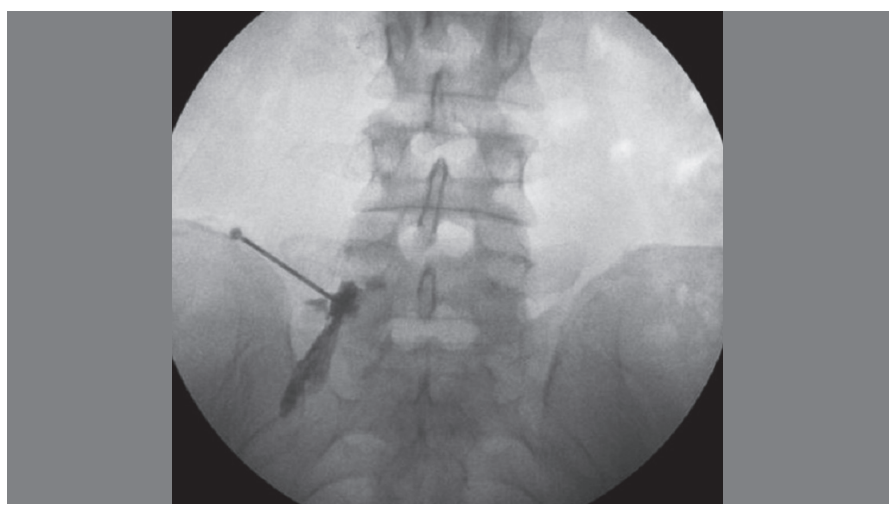

Figure 2. Fluoroscopy, post-contrast, showing the radicular trajectory.
The presence of paresthesia in the dermatome following the procedure is considered to be a clinical control of a correctly performed infiltration. Temporary muscle weakness may be noted in accordance with the innervation pattern. Pain relief should be assessed before and 15-30 minutes after the infiltration using a visual analog scale.

\section{Complications}

Complications associated with nerve root blocks are rare. However, there are reports of: 1) temporary non-positional headache (3.1\%); 2) Increased low back pain (2.4\%); 3) Increased sciatalgia (0.6\%); 4) Facial flushing (1.2\%); 5) Vasovagal reaction $(0.3 \%)$; 6) Systemic arterial hypertension (0.3\%); and 7) Elevated glycemia (0.3\%).

Houten reported three cases with persistent paraparesis and paraplegia that occurred immediately following the administration of a lumbar nerve root block. The sudden onset of neurological deficit and the imaging changes pointed to a vascular cause. ${ }^{11}$

\section{Diagnostic and therapeutic effectiveness}

Nerve root blocks provide rapid pain reduction.

Selective nerve root blocks are useful tools in the diagnosis of radicular pain in atypical presentation, particularly when the clinical profile does not correlate with the imaging study. This may be the case when the root is only compressed under a load. Diagnostic help is also provided in cases of multilevel impairment. Therapy is mainly focused on the immediate reduction of pain. If there is an inflammatory component, pain resolution may take several weeks and may be permanent due to the natural course of the benign disease.

Selective lumbar nerve root blocks were originally used with a contrast agent and lidocaine and were aimed at differentiating the different sources of pain in the lower limbs without a clinical diagnosis. Frequently, it is not possible to locate the exact involvement of the nerve root in a clinical neurological examination or in imaging exams. This is especially true with multilevel radicular impairment, shown by MRI. Numerous studies show that nerve root blocks are useful in cases where this close correlation does not exist. In the case of a positive response (i.e., the resolution of the sciatalgia), nerve root blocks allow the diagnosis of the affected nerve root, with a sensitivity of $100 \%$ in cases of bulging discs and with a positive predictive value of $75-95 \%$ in cases of foraminal stenosis. Only a few controlled studies that analyze the therapeutic efficacy of selective nerve root blocks have been published. ${ }^{12}$

\section{Epidural and Caudal Blocks}

Multisegment neural impairment can be treated with epidural anesthesia.

The treatment of cervical and lumbar pain syndromes using an epidural infiltration of corticosteroids was first described in 1952. Cervical epidural corticosteroid infiltration was mentioned for the first time in 1972 by Winnie, but did not achieve widespread acceptance, probably due to the high risk of complications. Epidural infiltrations include a variety of techniques, such as caudal (sacral), lumbar and cervicothoracic interlaminar. Unlike selective root nerve blocks, epidural steroid infiltration has the disadvantage that the pharmacological agent has to diffuse to the site of the inflammation and there is no guarantee that this will occur. ${ }^{13}$

Indications: In cases with involvement at various levels of non-specific sciatalgia, the epidural route has several advantages over selective nerve root blocks. Indications for epidural/caudal steroid injections are radicular compromise at several levels, dubious cases with sciatalgia, and central spinal stenosis.

\section{Caudal epidural block technique}

This technique is relatively easy to perform. However, the epidural sacral space should be filled so the solution reaches the target region, requiring the administration of a larger volume of the solution. Additionally, it was shown that the epidural space of the sacrum can be blocked in a considerable proportion of patients. The use of a small quantity of contrast to ensure that the steroid is applied in the epidural space is strongly recommended, (Figure 3) using contrast 
agents to document whether the drug is being administered to the proper space. The patients are invited to classify their pain using a visual analog scale (VAS) before and after the procedure.

The correct position of the needle should be documented by the contrast agent. (Figures 4 and 5)

Complications: Although complications are possible with any invasive procedure, reports with series of thousands of epidural steroid injections reveal that they are relatively safe. However, serious complications such as epidural abscess, arachnoiditis, epidural hematoma, liquoric fistula, paraparesis, and death have been reported.

Therapeutic efficacy: Most of the reports in the literature are from non-controlled, retrospective, observational studies. Despite the significant methodological flaws, the average success rate for epidural injections in $70 \%$. The efficacy of epidural steroid blocks

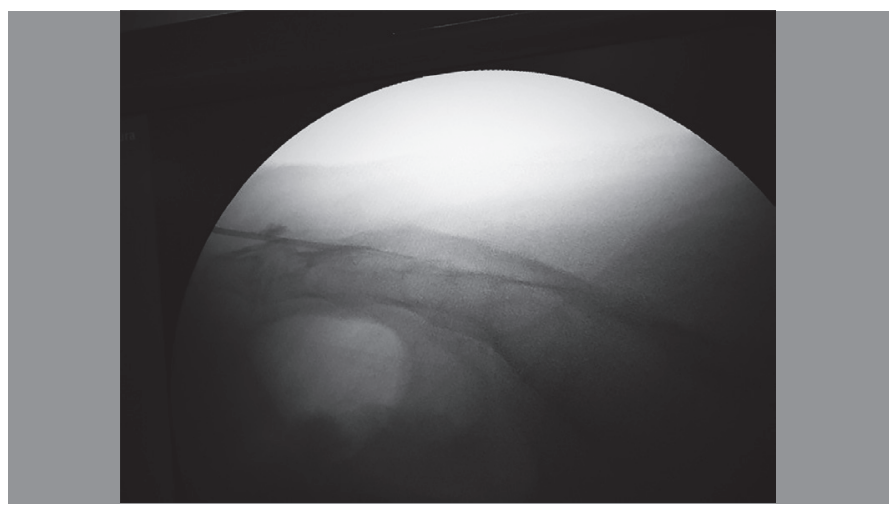

Figure 3. Fluoroscopy during the sacral block.

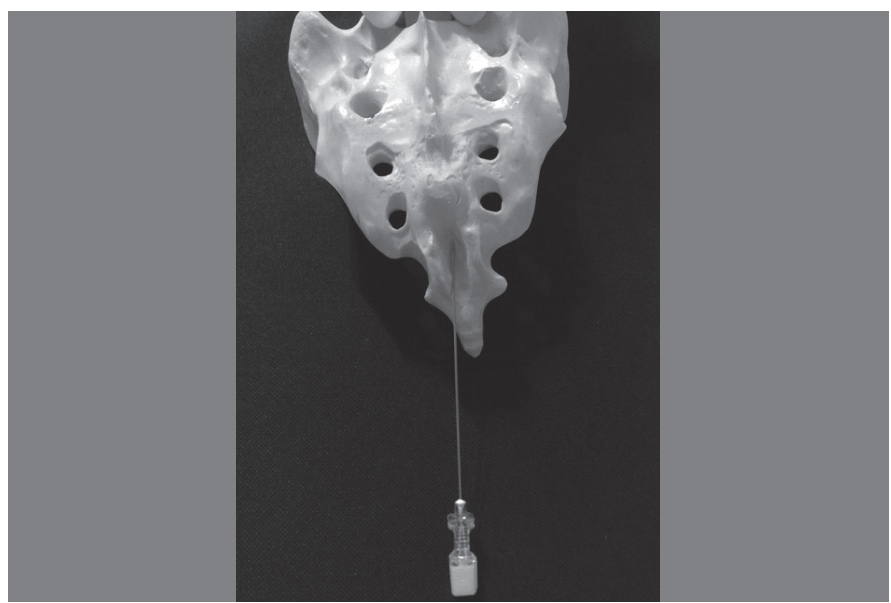

Figure 4. Anatomical specimen showing the entry point for the sacral infiltration (sacral hiatus).

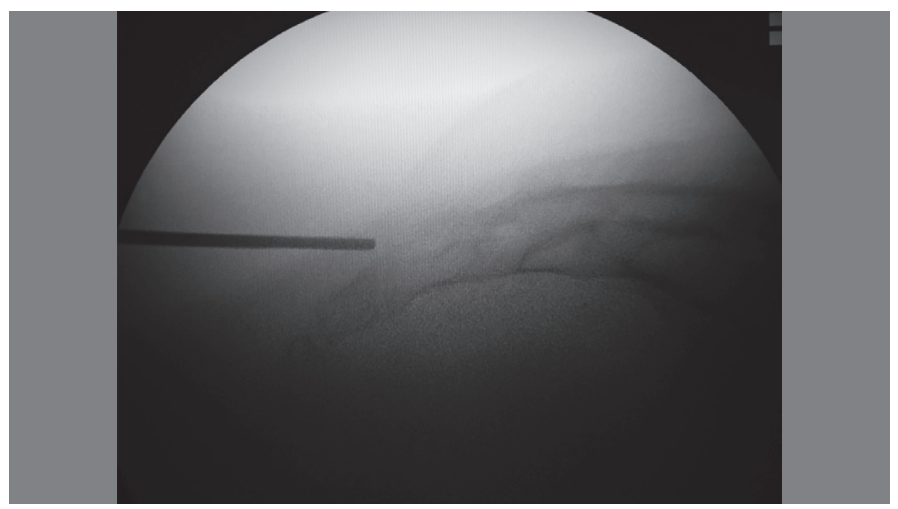

Figure 5. Preoperative localization of the infiltration site. is short as compared to selective infiltration due to the lack of a defined target. ${ }^{14,15}$

The therapeutic effect is often short-term.

\section{Infiltration of the facet joint}

Cervicalgia and lumbago can be caused by osteoarthritis of the facet joints.

Since the first account by Ghormley, joints have been recognized as a predominant source of low back pain. Its prevalence as a cause of low back pain varies from $7.7 \%$ to $75 \%$ depending on the diagnostic criteria. Mooney and Robertson showed that low back pain and referred pain can be caused by an injection of hypertonic saline solution into the joints. Today, many authors believe that the diagnosis of a facet syndrome can be based on pain relief from an intra-articular facet injection of an anesthetic or provocation of the pain by infiltration with hypertonic saline solution. ${ }^{16,17}$

Currently, facet blocks are used as a diagnostic and/or therapeutic method to eliminate pain, presumably originating in the joints.

Indications for facet joint blocks: In the same way as in disc degeneration, when the differentiation of symptomatic and asymptomatic facet osteoarthritis based only on imaging studies is not possible.

Therefore, when the facet joint block relieves the patient's symptoms, the pain was presumably the result of changes in the joints, being the only means of differentiating symptomatic states from asymptomatic ones.

Indications for a facet joint block: Differentiation of symptomatic from asymptomatic patients with spinal facet changes; for the short- and medium-term relief of low back pain in patients with a previous diagnosis.

\section{Lumbar facet joint block technique}

The blocks are performed guided by fluoroscopy with the patients in ventral decubitus, in order to visualize the lumbar joints, or the patient is turned and supported in an oblique frontal position or the $\mathrm{x}$-ray beam is angled accordingly.

The angle is generally between 30 and 40 degrees. After disinfection of the skin, the target joint is anesthetized with 2-3 ml of lidocaine. A spinal needle (22 gauge) is then inserted in a lateral direction (parallel to the axis of the x-ray) towards the joint. The correct location of the needle should be documented by injection of contrast agent.

Depending on the specific situation, either the medial, cranial, or caudal point of the joint is targeted. A minimal quantity of contrast medium $(<0.3 \mathrm{ml})$ is then injected under fluoroscopy to confirm the correct positioning of the needle. If an interarticular application is not possible, a periarticular injection is performed. The needle placement and the distribution of the contrast are documented by fluoroscopic control during the procedure. Then, $1.0 \mathrm{ml}$ of a mixture of local anesthetics (carbostesine or bupivacaine and steroids, for example, $40 \mathrm{mg}$ of triamcinolone) is injected.

The patients remain under surveillance for at least 15 minutes. All patients should be evaluated for the pain level before and 15-30 minutes after the infiltration using a visual analog scale. In addition, information about the course of pain relief is useful in the interpretation of the results.

Complications: While complications are possible with any invasive procedure, facet joint infiltrations prove to be safe due to their low incidence of complications.

Any technique involving a needle brings with it the risk of infection, which seems to be of little relevance in cases of facet blocks. The complications are retroperitoneal bleeding, allergic reactions, and lesions of the nerve sheath. There are several adverse effects, such as headache, nausea, and paresthesia, which are transitory. Obviously, secondary effects related to the pharmacology of the anesthetic agent and corticosteroids are possible. ${ }^{18}$

\section{Efficacy of the diagnosis and therapy of lumbar facet blocks}

Several authors suggest that the facet joint pain syndrome can be diagnosed based on pain relief from an infiltration of intra-articular anesthetic or provocation of pain from an infiltration of hypertonic 
saline solution followed by relief from the subsequent pain after an infiltration of anesthetics.

Dreyfuss concluded that there are no convincing findings, non-invasive radiographic studies, case histories, or physical examination results that allow the definitive identification of lumbar joints as the source of low back pain or lumbosciatalgia. ${ }^{19}$

One problem in interpreting the response to facet blocks is related to the innervation of the facet joint by 2-3 posterior segmental branches. A diagnostically accurate evaluation of infiltrations for the diagnosis of a symptomatic facet joint is difficult in the absence of a true gold standard.

There is much less information available about the therapeutic efficacy of facet joint blocks in relieving pain attributed to the joints. Carette selected 110 of the 190 patients whose relief was higher than $50 \%$ after an intra-articular facet block with $2 \mathrm{ml}$ of lidocaine in a double-blind randomized comparison of methylprednisolone and an isotonic saline infiltration. They reported immediate pain reduction in $76 \%$ versus $79 \%$ in the placebo group after six months of follow-up, but patients in the study group reported significantly greater pain relief ( $46 \%$ versus 15\%). The facets are innervated by several nerve segments, making the interpretation of the pain diffcult. ${ }^{20}$

\section{Contraindications for spinal injections}

Anatomical change or degenerative anomalies in which the positioning of the needle could be technically impossible are not in and of themselves a contraindication.

However, it is evident that these infiltrations can only be performed in patients without allergic reactions to the drugs and without coagulopathies.

Infiltration must not be performed in patients with bleeding disorders, taking anticoagulants, with infections or immunodeficiency syndromes, or allergic reactions to anesthetics or steroids.

Complications from facet joint blocks are rare..$^{21}$

\section{RESULTS}

Eighty-three (83) patients, 48 (58\%) of them female and 35 (42\%) of them male, were evaluated. (Table 1)

The ages of the patients were from 30 - 45 years of age, 18 patients (22\%); from 46 - 60 years of age, 25 patients (30\%); and older than 60 years of age, 40 patients (48\%). (Table 2 )

The duration from the onset of symptoms was three months in five patients (5\%), from four to six months in six patients (7\%), from 7 to 12 months in 39 patients (50\%), from 13 to 24 months in 12 patients (14\%), and more than 24 months in 21 patients (25\%). (Table 3 )

According to the visual analog scale for pain (VAS), the following data was collected: the VAS averaged 8.2 prior to the procedure, 4.2 in the immediate postoperative, 4.315 days following the procedure, 4.7 at 30 days, 5.2 at 45 days, and 5.590 days after the procedure. (Table 4)

Sacral infiltration was performed in 42 patients (51\%), sacral plus foraminal infiltration in 33 patients (40\%), facet joint infiltration in two patients $(2 \%)$, foraminal infiltration in two patients $(2 \%)$, and sacral plus facet joint infiltration in four patients (5\%). (Table 5)

Five patients $(6 \%)$ had pain improvement in the immediate postoperative period, but did not return for follow-up control nor was it possible to contact them.

Of the four patients (5\%) who had pain improvement during 15 to 45 day, one was indicated for surgery, another improved taking duloxetine, and another apparently had a socio-economic pain component.

Twenty patients had no pain improvement in the immediate postoperative period, of whom one patient (1.2\%) had vascular claudication and an aneurism of the abdominal aorta, one patient (1.2\%) had bilateral femoral acetabular impingement and underwent bilateral arthroscopic surgery, four patients (5\%) apparently had a socio-economic component of their pain (an expert medical statement was requested), one patient (1.2\%) was referred to psychiatry, 12 patients (15\%) were indicated for surgery (10 for decompression and arthrodesis and two for laminectomy and discectomy). One patient (1.2\%) had prostate cancer.
Table 1. Patients by sex

\begin{tabular}{c|c|c}
\hline Sex & $\#$ & $\%$ \\
\hline Female & 48 & 58 \\
\hline Male & 35 & 42 \\
\hline Total & 83 & 100 \\
\hline
\end{tabular}

Table 2. Patient ages in years.

\begin{tabular}{c|c|c}
\hline Age/years & $\#$ & $\%$ \\
\hline $30-45$ years & 18 & 22 \\
\hline $46-60$ years & 25 & 30 \\
\hline$>60$ years & 40 & 48 \\
\hline Total & 83 & 100 \\
\hline
\end{tabular}

Table 3. Duration of pain in months.

\begin{tabular}{c|c|c}
\hline Duration of pain/months & $\#$ & $\%$ \\
\hline 1 to 3 months & 5 & 6 \\
\hline 4 to 6 months & 6 & 7 \\
\hline 7 to 12 months & 39 & 47 \\
\hline 13 to 24 months & 12 & 14 \\
\hline$>24$ months & 21 & 25 \\
\hline Total & 83 & 100 \\
\hline
\end{tabular}

Table 4. Evaluation of pain according to VAS (Average score).

\begin{tabular}{c|c}
\hline Time period & Average VAS score \\
\hline Preoperative & 8.2 \\
\hline Immediate Postoperative & 4.2 \\
\hline 15 days & 4.3 \\
\hline 30 days & 4.7 \\
\hline 45 days & 5.2 \\
\hline 90 days & 5.5 \\
\hline
\end{tabular}

Table 5. Type of infiltration administered.

\begin{tabular}{c|c|c}
\hline Type of infiltration & $\#$ & $\%$ \\
\hline Sacral & 42 & 51 \\
\hline Sacral + Foraminal & 33 & 40 \\
\hline Facet & 2 & 2 \\
\hline Foraminal & 2 & 2 \\
\hline Sacral+ Facet & 4 & 5 \\
\hline Total & 83 & 100
\end{tabular}

Four patients (5\%) refused surgical treatment (decompression and lumbosacral spine arthrodesis) and decided to undergo infiltration, but with no improvement (VAS > 5).

One patient was indicated for surgery (decompression and lumbosacral spine arthrodesis), but with high comorbidity risks (morbid obesity and cardiopathy), and it was decided that infiltration would be performed, with improvement for 30 days.

\section{CONCLUSION}

There was a statistically significant reduction (average value) following the infiltrations (sacral, foraminal, and facet) according to the visual analog scale of 4 points in the immediate postoperative, and reductions of 3.9 points at 15 days, 3.5 points at 30 days, 3.1 points at 45 days, and 2.7 points at 90 days.

Sacral, foraminal, and facet corticosteroid infiltrations in the control of lumbago and lumbosciatalgia alleviate pain in the short term (30 days) and offer moderate relief in the long term (30 to 90 days), when 
they are correctly indicated. It is a low-risk procedure as compared to surgery. The results are satisfactory when the compression of the nerve root is associated with inflammation and edema, but not when they are caused by mechanical compression.

Sacral, foraminal, and facet infiltrations can be an alternative in the treatment of low back pain and lumbosciatalgia, as long as the correct indications are respected.

Performing infiltration may delay surgery and allow an earlier return to work, reducing public health spending.

Injections are administered close to the pathological lumbar and lumbosacral areas so the beneficial effects are greater.

Patients prefer to receive treatment that relieves their pain rapidly than to wait for a natural resolution to the problem.
Infiltration provides temporary pain relief (during the pain peak) for the time necessary for a spontaneous resolution of the radiculopathy.

Pain relief allows the patient to enter a physical therapy program more rapidly.

\section{ACKNOWLEDGEMENTS}

To the Team of the Spine Service of the Instituto de Ortopedia e Traumatologia de Passo Fundo.

All authors declare no potential conflict of interest related to this article.

CONTRIBUTION OF THE AUTHORS: Each author made significant individual contributions to the development of the manuscript. MFC and FLGL were the main contributors to the writing of the manuscript. MFC, FLGL, and FVL performed the surgeries, followed-up on the patients, and collected the clinical data. MFC and FLGL evaluated the statistical analysis data. MFC and FLGL conducted the bibliographical research and the review of the manuscript. All the authors contributed to the intellectual concept of the study.

\section{REFERENCES}

1. Brazil AV. Diagnóstico e tratamento das lombalgias e lombociatalgias. Rev Bras Reumatol.2004:44(6):419-5

2. Boos N, Aebi M. Spinal disorders: fundamentals of diagnosis and treatment. Zürich: Springer; 2008

3. Buenaventura RM, Datta S, Abdi S, Smith HS. Systematic review of therapeutic lumbar transforaminal epidural steroid injections. Pain Physician. 2009:12(1):233-51.

4. Camdem W. Hoch schuler: the pocket spine. Missouri: Quality Medical Publishing; 2006.

5. Cannon DT, Aprill CN. Lumbosacral epidural steroid injections. Arch Phys Med Rehabil.2000:81(3 Suppl 1):S87-98.

6. Karppinen J. Sciatica: studies of symptoms, genetic factors, and treatment with periradicular infiltration [dissertation] Oulu, Finland: University of Oulu; 2001.

7. Koc Z, Ozcakir S, Sivrioglu K, Gurbet A, Kucukoglu S. Effectiveness of physical therapy and epidural steroid injections in lumbar spinal stenosis. Spine (Phila Pa 1976).2009;34(10):985-9.

8. Manchikanti L, Helm S, Singh V, Benyamin RM, Datta S, Hayek SM, et al. An algorithmic approach for clinical management of chronic spinal pain. Pain Physician. 2009:12(4):E225-64.

9. Manchikanti L, Boswell MV, Datta S, Fellows B, Abdi S, Singh V, et al. Comprehensive review of therapeutic interventions in managing chronic spinal pain. Pain Physician. 2009:12(4):E123-98.

10. Macnab I. Negative disc exploration. An analysis of the causes of nerve-root involvement in sixty-eight patients. J Bone Joint Surg Am. 1971;53(5):891-903.

11. 1Houten JK, Errico TJ. Paraplegia after lumbossacral nerve root block: report of three cases. Spine J. 2002:2(1):70-5

12. Nicolau RJ, Rodrigues LM. Resultados terapeuticos das infiltrações epidurais, pela via transforaminal, guiadas por radioscopia em pacientes com radiculopatia lombosacral. Rev
Bras Med. 2009;66(12):27-31.

13. Lee $\mathrm{JH}, \mathrm{An} \mathrm{JH}$, Lee $\mathrm{SH}$. Comparison of the effect tivenesso finterlaminar and bilatera transforaminal epidural steroid injections in treatment of patients with lumbosacral disc herniation and spinal stenosis. Clin J Pain. 2009;25(3):206-10.

14. Vad VB, Bhat AL, Lutz GE, Cammisa F. Transforaminal epidural steroid injections in lumbo sacral radiculopathy: a prospective randomized study. Spine (PhilaPa 1976). 2002:27(1):11-6

15. Sayegh FE, Kenanidis El, Papavasiliou KA, Potoupnis ME, Kirkos JM, Kapetanos GA Efficacy of Steroid and nonsteroid caudal epidural injections for low back pain and sciatica: a prospective, randomized, double-blind clinical trial. Spine (Phila Pa 1976). 2009;34(14):1441-7.

16. Ghormley RK. Low back pain. With special reference to the articular facets, with presentation of an operative procedure. The Journal of the American Medical Association.1933;101(23):1773-7. Disponível em: http://jama.jamanetwork.com/article. aspx?articleid $=246300$.

17. Mooney V, Robertson J. The facet syndrome. Clin Orthop Relat Res. 1976;(115):149-56.

18. Tafazal S, NgL, Chaudhary N, Sell P. Corticosteroids in peri-radicular Infiltration for radicular pain: a randomized double blind control led trial. One year results and subgroup analysis. Eur Spine J. 2009;18(8):1220-5.

19. Dreyfuss $\mathrm{PH}$, Dreyer SJ, Herring SA. Lumbar zygapophysial (facet) joint injections. Spine. 1995:20(18):2040-7.

20. Carette S, Marcoux S, Truchon R, Grondin C, Gagnon J, Allard Y, et al. A controlled trial of corticosteroid injections into facet joints for chronic low back pain. N Engl J Med. 1991:325(14):1002-7.

21. Tonkovich-Quaranta LA, Winkler SR. Use of epidural corticosteroids in low back pain. Ann Pharmacother. 2000;34(10):1165-72 